JFFI. 2018; 5(2) 293-298

www.jurnal.farmasi.umi.ac.id/index.php/fitofarmakaindonesia

\title{
EFEKTIFITAS PEMANFAATAN POTENSI SENYAWA FENOLIK KUBIS UNGU (Brassica Oleraceae var.carpitata. L) SECARA INSTRUMEN UV-VIS
}

\author{
Mamat Pratama*, Aminah, Rizky Arfanita Mas'ud \\ Fakultas Farmasi, Universitas Muslim Indonesia \\ *mamatpratamas.farm@gmail.com
}

\begin{abstract}
Cabbage Purple (Brassica oleracea var. Capitata L.) is one of the genus Brasica genus that is widely available in Indonesia. Purple cabbage has many benefits because it has many content, among others, vitamins A, $B, C$ and E, mineral potassium, calcium, phosphorus, sodium and iron, sulforafan and contain anthocyanin. The purpose of this study was to perform and determine the total phenolic content of purple cabbage (Brassica oleracea var, capitata $\mathrm{L}$.). The method used in qualitative analysis is through color reaction by using specific reagent, while for quantitative analysis done by UV-Vis spectrofotometry method. For antioxidant activity test through absorbance analysis of acid error and sample absorbance from observation result on UV-Vis spectrophotometer. The results of this study contain phenolic compounds, as for the total phenolic content of methanol extracts that the purple cabbage (Brassica oleraceavar, capitata L.) Amounted to $1.9873 \mathrm{mgGAE} / \mathrm{g}$ extract.
\end{abstract}

Keywords: phenolic, gallic acid, Purple cabbage, Spectrophotometry Uv-Vis

\section{PENDAhUluan}

Kubis Ungu (Brassica oleracea var. capitata L.) merupakan salah satutanaman genus Brasica yang banyak terdapat diIndonesia. Kubis ungu mempunyai banyak manfaat karena mempunyai banyak kandungan antara lain vitamin A, B, C dan E, mineral kalium, kalsium, fosfor, natrium dan besi, sulforafan serta mengandung antosianin (Lin dkk, 2008). Antosianin juga tergolong senyawa flavonoid yang memiliki fungsi sebagai antioksidan alami dan memiliki kekuatan antioksidan 150 kali lebih kuat dari flavonoid (Neelufar dkk., 2012). Selain itu, antosianin mampu menghentikan reaksi radikal bebas dengan menyumbangkan hidrogen atau elektron pada radikal bebas dan menstabilkannya. Senyawa antioksidan dalam kubis ungu dapat diperoleh dengan cara ekstraksi. Dalam proses ekstraksi suatu bahan tanaman, banyak faktor yang dapat mempengaruhi kandungan senyawa hasil ekstraksi diantaranya: jenis pelarut, konsentrasi pelarut, metode ekstraksi dan suhu yang digunakan untuk ekstraksi. Penelitian ini bertujuan untuk mengetahui pengaruh variasi pelarut terhadap rendemen ekstrak kubis ungu dan panjang gelombang ( $\lambda$ ) maksimum serta mengetahui pengaruh metode ekstraksi kubis ungu terhadap aktivitas antioksidan. Flavanoid, tanin, lignin, antarquinon, asam fenolat dan kumarin merupakan senyawa fenolik yang tersebar dalam tumbuhan berupa fenol sederhana.

Senyawa fenolik telah diketahui memiliki berbagai efek biologis seperti aktivitas antioksidan melalui mekanisme sebagai pereduksi, penangkap radikal bebas, penghelatlogam, peredam terbentuknya oksigen singlet serta pendonor elektron (Karadeniz, 2005). Senyawa fenolik diketahui mampu menurunkan resiko kanker, penyakit jantung koroner, stroke, atherosclerosis, ospteoporosis, inflamasi, dan penyakit neurodegenerative lain (Surh, 2003).

Berdasarkan uraiaan di atas, maka dilakukan penelitian mengenai kandungan fenolik total yang terdapat pada ekstrak Kubis ungu (Brassica oleracea var. capitate L.) dengan menggunakan metode $\mathrm{Uv}-\mathrm{V}$ is untuk menambah data ilmiah tumbuhan ini, sehingga peranannya sebagai obat yang dapat menghasilkan efek yang dapat ditingkatkan dengan maksimal serta penggunaanya dapat lebih dipertanggung jawabkan oleh masyarakat.

\section{METODE PENELITIAN}

\section{A. Pengambilan dan Pengolahan Sampel}

Sampel kubis ungu (Brassica oleracea var. capitata L.) diambil pada pukul 08.00-11.00 diperoleh dari kecamatan Runaha Kabupaten Kunawe Selatan Provinsi Sulawesi Tenggara. Sampel kubis ungu (Brassica oleracea var. capitata L.) yang telah diambil selanjutnya dikeringkan dengan cara dianginanginkan. Setelah kering, sampel diserbukkan, kemudian diekstraksi dengan metode maserasi. 


\section{B. Pembuatan Ekstrak Sampel}

Ditimbang 600 gram kubis ungu (Brassica oleracea var. capitata L.) dimasukkan kedalam wadah maserasi, lalu ditambahkan pelarut etanol 96 $\%$ sebanyak $3.500 \mathrm{ml}$, dibiarkan selama 3 hari dalam bejana tertutup dan terlindungi dari cahaya matahari langsung sambil sesekali dilakukan pengadukan, setelah 3 hari dilakukan penyaringan untuk diperoleh ekstrak etanol cair dan ampasnya dimaserasi kembali dengan cairan penyari yang baru sampai jernih. Hasil penyarian yang diperoleh kemudian diuapkan hingga diperoleh ekstrak etanol kental.

\section{Analisis Kualitatif}

1. Uji Flavonoid

Ekstrak kubis ungu (Brassica oleracea var. capitata L.) sebanyak $1 \mathrm{~g}$ ditambahkan $10 \mathrm{~mL}$ methanol dan $5 \mathrm{~mL}$ petroleum eter, dikocok dan didiamkan. Lapisan metanol, diuapkan pada suhu $40^{\circ}$ C. Sisa larutan ditambahkan $5 \mathrm{~mL}$ etilasetat $\mathrm{P}$, disaring.

Maka dilakukan uji sebagai berikut:

Larutan uji sebanyak $1 \mathrm{~mL}$ diuapkan hingga kering, sisanya dilarutkan dalam 1-2 mL etanol (96\%) P, ditambahkan 0,5 g serbuk seng P dan $2 \mathrm{~mL}$ asam klorida $2 \mathrm{~N}$, didiamkan selama 1 menit. Ditambahkan 10 tetesasam klorida pekat. Jika terbentuk warnah merah intensif menunjukkan adanya flavanoid (glikosida-3-flavonol).

Larutan uji sebanyak $1 \mathrm{~mL}$ diuapkan, sisa dilarutkan dalam $1 \mathrm{~mL}$ etanol (95\%) P, ditambahkan $0,1 \mathrm{~g}$ serbuk magnesium $\mathrm{P}$ dan 10 tetes asam klorida P. Jika terjadi warna merah jingga sampai merah ungu, menunjukkan adanya flavanoid. Jikawarnakuning jingga menunjukkan adanya flavonoid.

\section{Tanin}

Ekstrak sebanyak $1 \mathrm{~g}$ ditambah $15 \mathrm{ml}$ air panas. Larutan dipanaskan hingga mendidih selama 5 menit, disaring. Percobaan dilakukan sebagai berikut:

a. Filtrat sebanyak $5 \mathrm{~mL}$ ditambah beberapa tetes $\mathrm{FeCl}_{3} 1 \%$, menghasilkan warna hijau violet.

b. Filtrat sebanyak $5 \mathrm{~mL}$ ditambahkan gelatin $10 \%$ membentuk endapan putih.

c. Filtrat sebanyak $5 \mathrm{~mL}$ ditambahkan $\mathrm{NaCl}$-gelatin (larutan gelatin $1 \%$ dalam larutan $\mathrm{NaCl} 10 \%$ ) membentuk endapan putih.

\section{Analisis Kuantitatif Senyawa Fenol}

1. Pembuatan Pereaksi $\mathrm{Na}_{2} \mathrm{CO}_{3} 7 \%$

Ditimbang sebanyak 3,5 gram $\mathrm{Na}_{2} \mathrm{CO}_{3}$ kemudian dilarutkan dengan aquadest steril hingga $50 \mathrm{ml}$.

2. Penetapan Kadar Fenolik Total

Penetapan kadar fenolik total pada ekstrak metanol kulit buah kubis ungu (Brassica oleracea var. capitata L.) merujuk pada prosedur Nugroho, et al (2012) dengan beberapa modifikasi.

3. Pembuatan Larutan Standar Asam Galat

Larutan standar asam galat $1000 \mathrm{ppm}$ dibuat dengan menimbang $10 \mathrm{mg}$ asam galat dilarutkan dengan methanol p.a hingga volume $10 \mathrm{~mL}$. Dari larutan stok dipipet sebanyak $1 \mathrm{~mL}$ diencerkan dengan methanol p.a hingga volume $10 \mathrm{~mL}$ hingga dihasilkan konsentrasi $100 \mathrm{ppm}$, kemudian dibuat konsentrasi 0.2, 0.4, 0.6, 0.8 dan $1 \mathrm{ppm}$.

4. Pengukuran Larutan Standar Asam Galat

Untuk masing-masing konsentrasi 8, 12, 16, 20 dan 24 ppm ditambahkan dengan $0,4 \mathrm{~mL}$ reagen Folin-Ciocalteau dikocok dan dibiarkan 4-8 menit, tambahkan 4,0 mL larutan $\mathrm{Na}_{2} \mathrm{CO}_{3} 7 \%$ kocok hingga homogen. Tambahkan aquades steril hingga $10 \mathrm{~mL}$ dan diamkan selama 2 jam pada suhu ruangan. Ukur serapan pada panjang gelombangmaksimum $755 \mathrm{~nm}$, lalu buat kurva kalibrasinya, hubungan antara konsentrasi asam galat $(\mu \mathrm{g} / \mathrm{mL})$ dengan absorbansi.

5. Pembuatan larutan sampel ekstrak kubis ungu (Brassica oleracea var. capitata L.)

Ditimbang ekstrak kubis ungu sebanyak 10 mg kemudian dilarutkan dengan $10 \mathrm{~mL}$ etanol.

6. Penetapan kadar fenolik total ekstrakkubis ungu (Brassica oleracea var. capitata L.)

Dipipet sebanyak 0,5 mL larutan dari kubis ungu (Brassica oleracea var. capitata L.) Ditambahkan dengan $0,4 \mathrm{~mL}$ reagen FolinCiocalteau dikocok dan dibiarkan 4-8 menit, tambahkan 4,0 mL larutan $\mathrm{Na}_{2} \mathrm{CO}_{3} 7 \%$ kocok hingga homogen menggunakan. Tambahkan aquades steril hingga $10 \mathrm{~mL}$ dan diamkan selama 2 jam pada suhu ruangan.

Ukur serapan pada panjang gelombang serapan maksimum $755 \mathrm{~nm}$ yang akan memberikan kompleks biru. Lakukan 3 kali pengulangan sehingga kadar fenol yang diperoleh, hasilnya dinyatakan sebagai mg ekuivalen asam galat/g ekstrak. 


\section{HASIL DAN PEMBAHASAN}

A. Hasil Penelitian

Tabel 1. Persen rendamen ekstrak etanol kubis ungu (Brassica oleracea var. capitata L.)

\begin{tabular}{ccccc}
\hline $\begin{array}{c}\text { Jenis } \\
\text { pelarut }\end{array}$ & $\begin{array}{c}\text { Jumlah } \\
\text { Pelarut }\end{array}$ & $\begin{array}{c}\text { Berat } \\
\text { Sampel }(\mathbf{g})\end{array}$ & $\begin{array}{c}\text { Berat } \\
\text { Ekstrak }(\mathbf{g})\end{array}$ & $\begin{array}{c}\text { Rendamen ekstrak } \\
(\%)\end{array}$ \\
\hline Etanol $96 \%$ & $4000 \mathrm{~mL}$ & $500 \mathrm{~g}$ & $22,0634 \mathrm{~g}$ & 4,41286 \\
\hline
\end{tabular}

Tabel 2. Hasil uji kualitatif senyawa fenolik fraksi kubis ungu (Brassica oleracea var. capitata L.) menggunakan $\mathrm{FeCl}_{3}$

\begin{tabular}{cccc}
\hline Sampel & $\begin{array}{c}\text { Uji fenolik } \\
\left(\mathbf{F e C l}_{3}\right)\end{array}$ & $\begin{array}{c}\text { Hasil } \\
\text { pengamatan }\end{array}$ & $\begin{array}{c}\text { Berdasarkan literature } \\
\text { (Seafast Centre, 2012) }\end{array}$ \\
\hline Kubis Ungu & + & Ungu & merah, ungu, dan biru,
\end{tabular}

\begin{tabular}{ll}
\hline Keterangan: & $(+)=$ adanya fenolik \\
& $(-)=$ tidak adanya fenolik
\end{tabular}

Tabel 3. Hasil pegukuran larutan standard asam gallat pada panjanggelombang $726 \mathrm{~nm}$ dengan menggunakan spektrofotometer UV-Vis

\begin{tabular}{ccc}
\hline No & Sampel ID & Absorban \\
\hline 1 & asam galat $8 \mathrm{ppm}$ & 0,215 \\
2 & asam galat $12 \mathrm{ppm}$ & 0,372 \\
3 & asam galat $16 \mathrm{ppm}$ & 0,479 \\
4 & asam galat $20 \mathrm{ppm}$ & 0,603 \\
5 & asam galat $24 \mathrm{ppm}$ & 0,726 \\
\hline
\end{tabular}



Gambar 1. Hasil runnig kurva kalibrasi asam galat pada panjang gelombang $726 \mathrm{~nm}$

Tabel 4. Hasil pengukuran sampel ekstrak metanol kubis ungu dengan penambahan folin-ciocalteau dan $\mathrm{Na}_{2} \mathrm{HCO}_{3}$ pada panjang gelombang $726 \mathrm{~nm}$ dengan menggunakan spektrofotometer Uv-Vis

\begin{tabular}{ccc}
\hline No & Sampel ID & Absorban \\
\hline 1 & Blank & 0,000 \\
2 & ekstrak metanol kubis ungu R1 & 0,386 \\
3 & ekstrak metanol kubis ungu R2 & 0,394 \\
4 & ekstrak metanol kubis ungu R3 & 0,410 \\
\hline
\end{tabular}


Tabel 5. Hasil kurva running asam galat pada panjang gelombang700 - $800 \mathrm{~nm}$ secara spektrofotometri Uv-Vis

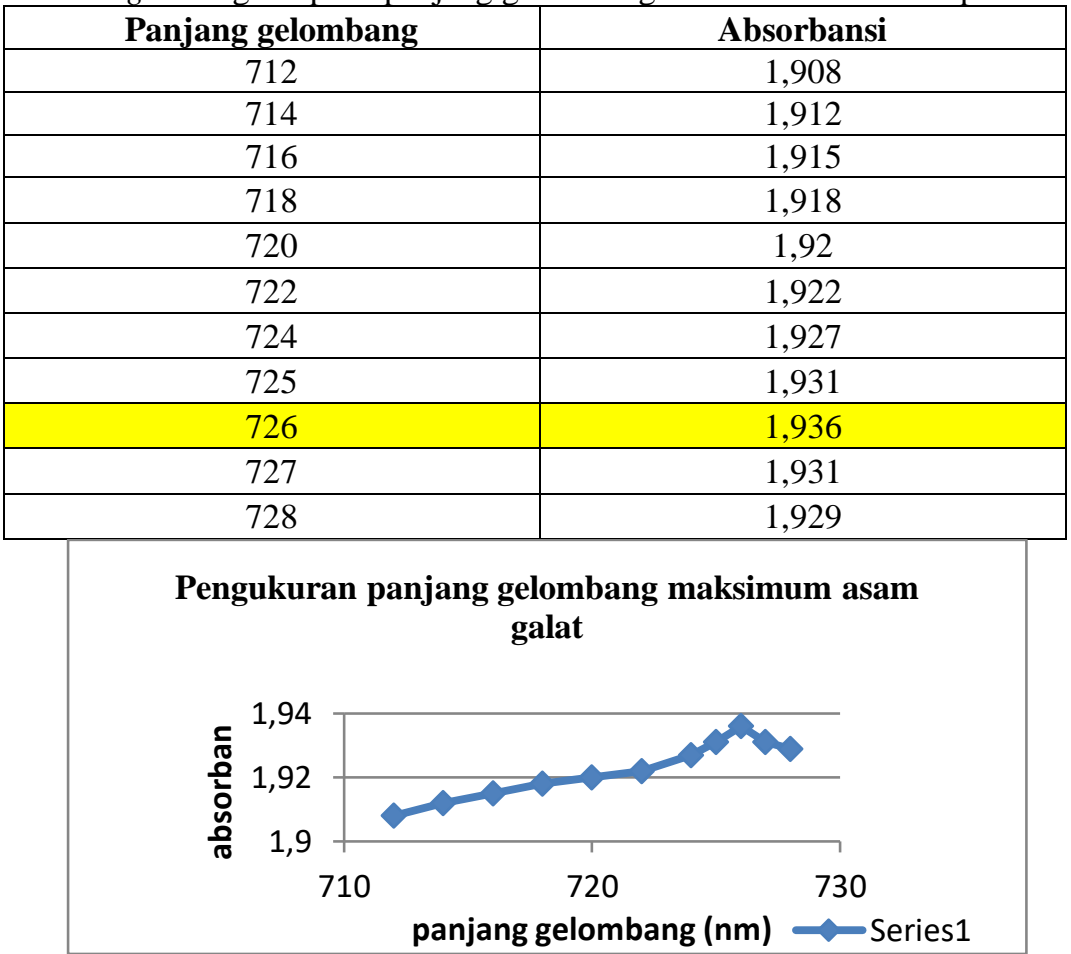

Gambar 2. Hasil runnig kurva baku asam galat pada panjang gelomban $600 \mathrm{~nm}-800 \mathrm{~nm}$

Tabel 6. Hasil analisis kuantitatif fraksi kubis ungu (Brassica oleracea var. capitate L.)

\begin{tabular}{cccccc}
\hline Replikasi & $\begin{array}{c}\text { Absorbansi } \\
(\mathbf{y})\end{array}$ & $\begin{array}{c}\text { Absorban } \\
\text { kontrol } \\
\text { ekstrak }\end{array}$ & $\begin{array}{c}\text { Kandungan } \\
\text { fenolik total } \\
\text { awal }(\mathbf{m g} / \mathbf{L})\end{array}$ & $\begin{array}{c}\text { Kandungan } \\
\text { total fenolik } \\
\text { (mgGAE/g } \\
\text { fraksi) }\end{array}$ & $\begin{array}{c}\text { Rata-rata } \\
\text { kandungan fenolik } \\
\text { total mgGAE/g }\end{array}$ \\
\hline 1 & 0,386 & 0,000 & $3,903 \mathrm{mg} / \mathrm{L}$ & $\begin{array}{c}1,9515 \mathrm{mgGAE} / \mathrm{g} \\
1,9835\end{array}$ & \\
2 & 0,394 & 0,000 & $3,967 \mathrm{mg} / \mathrm{L}$ & $\begin{array}{c}\mathrm{mgGAE} / \mathrm{g} \\
\mathrm{mgGa}\end{array}$ & $1,9873 \mathrm{mgGAE} / \mathrm{g}$ \\
3 & 0,410 & 0,000 & $4,094 \mathrm{mg} / \mathrm{L}$ & $2,027 \mathrm{mgGAE} / \mathrm{g}$ & \\
\hline
\end{tabular}

\section{B. PEMBAHASAN}

Kubis Ungu (Brassica oleracea var. capitata L.) merupakan salah satutanaman genus Brasica yang banyak terdapat diIndonesia. Kubis ungu mempunyai banyak manfaat karena mempunyai banyak kandungan antara lain vitamin A, B, C dan E, mineral kalium, kalsium, fosfor, natrium dan besi, sulforafan serta mengandung antosianin (Lin dkk, 2008).

Tujuan penelitian ini adalah untuk menentukan kadar fenolik total kubis ungu (Brassica oleracea var. capitataL.) Senyawa fenolik merupakan kelompok terbesar metabolit sekunder pada tumbuhan. Senyawa ini termasuk ke dalam alkohol aromatik karena gugus hidroksilnya selalu melekat pada cincin benzen (Pengelly 2006, h. 15). Senyawa fenolik merupakan molekul yang bertindak sebagai antioksidan untuk mencegah penyakit jantung, mengurangi peradanganserta mengurangi tingkat mutagenesis pada sel manusia (Khoddami, Wilkes dan Roberts 2013, h. 2328).

Langkah awal untuk memperoleh ekstrak yang nantinya akan digunakan dalam penelitian ini adalah proses ekstraksi. Dimana metode ekstraksi yang digunakan adalah maserasi. Metode maserasi menjadi pilihan dalam proses ekstraksi karena metode ini merupakan metode yang paling sederhana dan tidak membutuhkan bantuan pemanasan mengingat sampel yang digunakan mengandung gugus hidroksil yang akan terurai ketika ada pemanasan. Pelarut yang digunakan dalam proses ekstraksi kubis ungu (Brassica oleracea var. capitataL.) adalah etanol $96 \%$. Setelah diperoleh ekstrak etanol cair, kemudian dilakukan remaserasi sebanyak 2 kali. Semua ekstrak etanol cair yang diperoleh kemudian 
dikumpulkan dan diuapkan untuk memperoleh ekstrak etanol kental kubis ungu (Brassica oleracea var. capitate L.)

Dari hasil penguapan ekstrak etanol kubis ungu (Brassica oleracea var. capitate L.) diperoleh persen rendamen sebesar $4,41286 \%$. Adapun tujuan dilakukannya penentuan persen rendamen ekstrak adalah untuk mengetahui kandungan metabolit sekunder yang tersari oleh pelarut yang digunakan namuntidak dapat menentukan komponen kimia yang tersari.

Selanjutnya dilakukan pengujian kualitatif untuk mengetahui kandungan fenolik yang terdapat pada fraksi kubis ungu (Brassicaoleracea var. capitate L.), dengan menggunakan besi (III) klorida $\left(\mathrm{FeCl}_{3}\right)$ dan diamati perubahan warna yang terbentuk. Adapun perubahan warna yang terbentuk pada perlakuan ini adalah terbentuknya warna ungu yang menandakan bahwa sampel fraksi kubis ungu (Brassica oleracea var. capitate L.) mengandung senyawa fenolik.

Penetapan kadar fenolik total dilakukan dengan menggunakan asam galat sebagai larutan standar. Asam galat termasuk kedalam senyawa fenolik turunan asam hidroksibenzoat yang tergolong asam fenol sederhana. Asam galat menjadi pilihan standar dikarenakan ketersediaan substansi yang stabil dan murni (Syarif, Sari dan Ahmad 2016, h. 105). Penetapan kadar fenolik total dilakukan dengan menggunakan metode Follin-Ciocalteau dimana, reagent FollinCiocalteau direaksikan dengan asam galat sehingga membentuk larutan berwarna biru yang dapat diukur absorbansinya pada spektrofotometer dengan panjang gelombang $726 \mathrm{~nm}$.

Prinsip metode Follin-Ciocalteau adalah terbentuknya senyawa kompleks berwarna biru keunguan yang dapat diukur absorbansinya. Pereaksi ini mengoksidasi fenolat (garam alkali) atau gugus fenolik-hidroksi mereduksi asam heteropoli (fosfomolibdat-fosfotungstat) yang terdapat dalam pereaksi Folin Ciocanteau menjadi suatu kompleks molibdenum-tungsten. Senyawa fenolik bereaksi denga reagen Folin Ciocalteau hanya dalam suasana basa agar terjadi disosiasi proton pada senyawa fenolik menjadi ion fenolat. Untuk membuat kondisi basa digunakan $\mathrm{NaHCO}_{3}$ $7,5 \%$. Gugus hidroksil pada senyawa fenolik bereaksi dengan reagen Folin Ciocalteau membentuk kompleks molibdenum-tungsten berwarna biru yang dapat dideteksi dengan menggunakan spektrofotometer UV-Vis (Alfian dan Susanti 2012, hh. 77-78).

Dalam menentukan kadar fenolik total, langkah awal yang perlu dilakukan adalah penentuan panjang gelombang maksimal dengan merunning larutan standar pada panjang gelombang 600-800 nm. Dan pada penelitian ini diperoleh panjang gelombang maksimal $726 \mathrm{~nm}$. Larutan standar dengan konsentrasi 8, 12, 16, 20 dan 24 ppm kemudian diukur absorbansinya pada panjang gelombang $726 \mathrm{~nm}$ yang didapatkan dari hasil running panjang gelombang maksimal pada spektrofotometer UV-Vis. Pengukuran absorbansi standar dilakukan agar mendapatkan kurva kalibrasi untuk memperoleh persamaan regresi linear dengan tujuan untuk melihat apakah sampel yang digunakan dalam penelitian memenuhi standar ataupun tidak.

Berdasarkan kurva kalibrasi asam galat diperoleh persamaan regresi linear $\mathrm{Y}=0,1253 \mathrm{x}+$ 0,1031 dengan nilai koefisien korelasi (r) = 0,9979. Setelah diperolah absorbansi dari masingmasing konsentrasi larutan standar dan mendapatkan persamaan regresi linear maka selanjutnya dilakukan proses penetapan kadar fenolik total fraksi kubis ungu (Brassica oleracea var. capitate L.). penetapan kadar fenolik total fraksi kubis ungu (Brassica oleracea var. capitate L.) dilakukan dengan melakukan 3 kali replikasi dengan tujuan untuk meminimalkan kesalahan yang mungkin terjadi pada saat pengerjaan.

\section{KESIMPULAN}

Berdasarkan penelitian yang telah dilakukan di Laboratorium Kimia Farmasi Universitas Muslim Indonesia, maka dapat disimpulkan bahwa kubis ungu (Brassica oleracea var. capitate L.) mengandung senyawa fenolik, adapun kadar fenolik total pada ekstrak metanol bahwa kubis ungu (Brassica oleracea var. capitata L.) sebesar 1,9873 mgGAE/g ekstrak.

\section{DAFTAR PUSTAKA}

Balls M, James, dan Jacqueline, 1991. Animals and Alternatives in Toxicology.

Darmansjah I., 1995. Toksikologi Dasar dalam Farmakologi dan Terapi.

Bagian.Farmakologi Universitas Indonesia, Jakarta.

$\begin{array}{cccr}\text { Donatus } & \text { I.A., 2001. } & \text { Toksikologi } & \text { Dasar. } \\ \text { Laboratorium } & \text { Farmakologi } & \text { dan } \\ \text { Toksikologi. UGM Press, Yogyakarta. } & \end{array}$

Ganong W.F., 2003. Buku Ajar Fisiologi Kedokteran (terjemahan). Edisi ke-20.Penerbit Buku Kedokteran EGC, Jakarta.

Gunawan, G.S., 2007. Farmakologi Terapi (edisi 5). Badan Farmakologi Fakultas Kedokteran Universitas Indonesia. Jakarta

Jassin,1987. Zoologi Vertebrata.Depkes RI. Jakarta 
Koeman J.H., 1987. Pengantar Umum Toksikologi (terjemahan). Gajah Mada University Press, Yogyakarta.

Kusumo, S., Hasanah, M., Moeljopawiro, S., Thohari, M., Subandriyo., Hardja, M., Nurhadi, A., dan Kasim, H., 2002. Panduan Karakterisasi dan Evaluasi Plasma Nutfah Talas. Bogor: Departemen Pertanian Badan Penelitian dan Pengembangan Pertanian Komisi Nasional Plasma Nutfah.

Leong, A.C., Yoshinori K., Masakuni T., Hironori I., Hirosuke O., dan Hajime T., 2009. Flavonoid glycosides in the shoot system of Okinawa Taumu (Colocasia esculenta S.). J. Food Chem. 2009.07.00

Loomis, T.A., 1978. Toksikologi Dasar. IKIP Press, Semarang. .

Lu F.C., 1995. Toksikologi Dasar : Asas, Organ, Sasaran, dan Penilaian Resiko. Edisi ke-2. UI Press, Jakarta.

Malole, M. B. M., dan CSU Pramono., 1989. Penggunaan Hewan-hewan Percobaan di Laboratorium. PAU-Bioteknologi IPB, Bogor.

Mukono, H.J., 2005. Toksikologi Lingkungan. Airlangga University Press Surabaya

Rukmana, R., 1997. Ubi jalar budidaya dan pasca panen. Penerbit kanisius. Yogyakarta.

Siregar CJP, Sri, Sanggariwati, Sukirno, Yuharni, dan Srikandi D., 1991. Prosedur Operasional Baku Uji Toksisitas. Pusat Pemeriksaan Obat dan Makanan.

Siswandono dan Bambang, 1995. Kimia Mediasinal. Airlangga University Press, Surabaya 